\title{
Rational Polypharmacy in the Acute Therapy of Major Depression
}

\author{
Per Bech and Claudio Csillag \\ Psychiatric Research Unit, Mental Health Centre North Zealand, \\ University of Copenhagen \\ Denmark
}

\section{Introduction}

Monotherapy is a basic principle in all branches of clinical medicine, including psychiatry. It is a scientific principle where we are making an attempt to clarify one single therapeutic step, its wanted and unwanted effects, in isolation. According to this principle we make sure to start with the least aggressive approach. However, in daily clinical practice polypharmacy might be considered when treating patients who have only a partial response to the first prescribed monotherapeutic trial.

With the introduction of the antidepressive medication in the 1960s we had access to two different classes of antidepressants: the tricyclic antidepressants (TCAs) and the monoamine oxidase inhibitors (MAO-Is). Together these drugs cover serotonin, noradrenaline and dopamine effects in the brain, which we still consider important to stabilize in the acute therapy of major depression. On the other hand, both classes of drugs have many other actions which are often considered as side-effects.

The new generation of antidepressants became available in the late 1980s and most of them are much more selective in their action than the first generation antidepressants. Therefore they have less severe side effects, but must often be combined to obtain the same antidepressive effectiveness as the first generation antidepressants.

In the following text we will introduce the most patient-friendly approach to obtain a rational polypharmacy in the acute therapy of major depression. This is based not only on the traditional classification of drugs by receptor profile and expected mechanism of action in the brain, but also on clinical monitoring by use of valid rating scales for both the wanted and unwanted effects upon the mind.

\section{The disease-centre model of antidepressants}

The tricyclic antidepressants (TCAs) and the monoamine oxidase inhibitors (MAO-Is) are the first generation of effective antidepressants. These types of drugs showed that major depression could be treated like other medical conditions, by covering the acute short-term treatment of four to eight weeks followed by a medium-term treatment, and the continuation phase of four to eight months (the relapse-prevention phase). 
It was from this evidence that a "disease-centred" model emerged, in which antidepressants were seen to help the brain of the depressed patient by restoring the neuropathological states.

Over the fifty years since the TCAs and MAO-Is were first marketed, their biological mechanisms of action in the brain have been extensively studied. All the TCAs are both serotonin and noradrenaline reuptake inhibitors, but also act on many other mechanisms (e.g. histamine blockers). However, they have no action on dopamine. At the receptor level they all stimulate the serotonin $1 \mathrm{~A}$ receptor and the most potent of them, amitriptyline, is also a serotonin receptor 2A blocker. The MAO-Is, as they inhibit the enzyme monoamine oxidase, act on both serotonin and noradrenaline as well as on dopamine. The MAO-Is probably also act on other processes in the brain, e.g. vitamin B6. We do know, however, that the MAO-Is are not antihistamines.

Taken together the TCAs and the MAO-Is can be considered to be non-selective or multidimensional drugs, comparable to a more or less rational polypharmacy at the receptor level. This is even when used as monotherapy in the acute therapy of major depression.

The new generation of selective antidepressants (the selective serotonin reuptake inhibitors (SSRIs)), or the selective noradrenaline and serotonin reuptake inhibitors (SNRIs) have a selective mechanism of action, thus avoiding polypharmacy. However, the new generation antidepressants such as the SSRIs or SNRIs are less effective than the TCAs. Even within the TCAs, amitriptyline was found to be superior to imipramine both in the acute therapy of depressed patients and in the relapse-prevention phase .

\section{Using the Hamilton depression scale $\left(H A M-D_{17}\right)$ to direct polypharmacy}

When discussing the difference between the first generation and the second generation of antidepressants, Moncrieff and Cohen claimed that the Hamilton Depression Scale (HAM-D) contains many items that are not specific to depression, for example: “... three items on sleep, two on anxiety and one on agitation can score up to 18 points (a total score between 19 - 22 on the Hamilton Rating Scale for Depression indicates severe depression). On these items, any drug with sedative effects would be likely to outperform placebo..."

However, with correct clinical use, the Hamilton Depression Scale covers the three clinical dimensions that have to be taken into account in the acute therapy of major depression in order to institute rational polypharmacy within the "disease-control" model of antidepressants. This correct clinical approach is obtained by use of the tripartite A,B,C HAM-D.

The HAM- $\mathrm{D}_{17}$ is a multidimensional depression rating scale, implying that a total summed score of all the 17 items is not always a sufficient statistic, i.e. a profile score is needed.

Recently Santen et al. studied all placebo-controlled trials with the SSRI drug paroxetine and demonstrated that the most sensitive items in the HAM- $\mathrm{D}_{17}$ to discriminate between paroxetine and placebo were the six items in the HAM- $\mathrm{D}_{6}$. Actually, when using the HAM$\mathrm{D}_{17}$, the difference from baseline to endpoint between paroxetine $20 \mathrm{mg}$ daily and placebo did not reach the level of $\mathrm{P}<0.05$, in contrast to HAM- $\mathrm{D}_{6}(\mathrm{P}=0.03)$. Furthermore, they found that with paroxetine $10 \mathrm{mg}$ daily no difference to placebo was reached at the level of $\mathrm{P}<0.05$ for either HAM- $\mathrm{D}_{17}$ or $\mathrm{HAM}_{-} \mathrm{D}_{6}$, indicating a dose response pattern. 
Pure depression

1. $\square$ Depressed mood
2. $\square$ Guilt
7. $\square$ Activities and interests
8. $\square$ Psychomotor retardation
10. $\square$ Anxiety, psychic
13. $\square$ Somatic symptoms - general

(A)

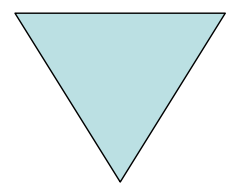

(C)

Suicide risk behaviour

3. Suicidal thoughts

16.

Insight
Physiological arousal symptoms

(B)

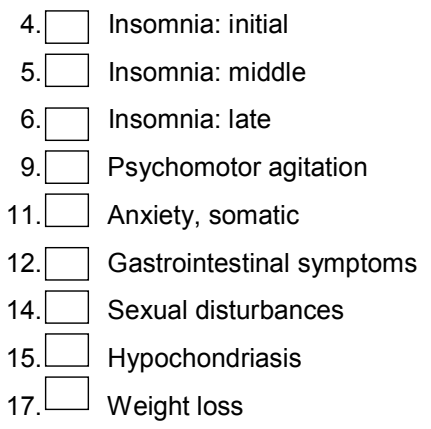

(B) HAM-D $_{9}$
Total score:

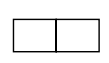

HAM-D ${ }_{17}$ Total score: $(\mathrm{A}+\mathrm{B}+\mathrm{C})$

Fig. 1. ABC version of the depression scale (HAM-D)

Fig. 1. Shows the three major components A, B, C in the HAM-D $\mathrm{D}_{17}$. Domain A in Figure 1 covers the six pure depression symptoms in the HAM-D as used by experienced psychiatrists when measuring the severity of depressive states. Using item response theory models, the invariant item ordering of the HAM- $\mathrm{D}_{6}$ items was found by their prevalence at baseline and at the endpoint in clinical trials of antidepressants. In the archetypical trial with the TCA amitriptyline in the setting of general practice, Paykel showed that all items in the HAM- $\mathrm{D}_{6}$ discriminated between the TCA and placebo in both mild and moderate degrees of depression. Among the other HAM-D items only the sleep symptom showed discrimination, implying that amitriptyline is a sedative antidepressant. When comparing amitriptyline with the most sedative new generation antidepressant mirtazapine in placebocontrolled trials, it was the HAM- $\mathrm{D}_{6}$ items that significantly differentiated between the active drugs and placebo, thereby prefiguring Moncrieff and Cohen's critical remarks on the use of the HAM-D 17 in measured outcome.

Domain B in Figure 1 covers the physiological arousal symptoms, including the "sedative" HAM-D items selected by Moncrieff and Cohen. These nine symptoms (HAM-D $)$ in Figure 1 were included by Hamilton in his HAM-D $\mathrm{D}_{17}$ because they were found very common and distressing by the depressed patients themselves. As non-sedative antidepressants both the SSRIs and the SNRIs as well as the MAO-Is have to be combined with the antidepressants with antihistaminic action and/or serotonin receptor 2 blockers when the HAM-D profile is in operation in the depressed patients, i.e. when polypharmacy is rationally needed. In therapy-resistant depression it is often the physiological arousal symptoms that have been inadequately reduced. 
Domain $C$ in Figure 1 covers the two remaining items in HAM-D 17 (suicidal thoughts and lack of insight). Due to the obvious clinical relevance of these items, their assessment is crucially important in the acute therapy of patients with major depression. It has even been questioned that SSRIs might induce suicidal thoughts over the first weeks of therapy.

\section{Patient related inventory of side effects $\left(\mathrm{PRISE}_{20}\right)$}

Table 1 shows the Patient Rated Inventory of Side Effects (PRISE), modified to monitor domain B selectively with 20 items (PRISE 20 ).

The first 17 items listed in Table 1 are derived from the original PRISE and the remaining 3 items at the bottom in Table 1 are derived from the UKU (Udvalg for Kliniske Undersøgelser) subscale for antidepressants. The UKU scale is a clinician-rated scale whereas the PRISE is a patient-reported questionnaire.

\begin{tabular}{|lcccc|}
\hline \multicolumn{4}{|l}{ Have you had any of these side effects over the past two weeks? } \\
& No & Yes, but tolerable & Yes - Distressing \\
\hline 1. Dry mouth & $\square$ & $\square$ & $\square$ \\
2. Nausea & $\square$ & $\square$ & $\square$ \\
3. Diarrhoea & $\square$ & $\square$ & $\square$ \\
4. Constipation & $\square$ & $\square$ & $\square$ \\
\hline 5. Dizziness & $\square$ & $\square$ & $\square$ \\
6. Palpitations & $\square$ & $\square$ & $\square$ \\
7. Sweating & $\square$ & $\square$ & $\square$ \\
\hline 8. Headache & $\square$ & $\square$ & $\square$ \\
9. Tremor & $\square$ & $\square$ & $\square$ \\
\hline 10. Difficulty sleeping & $\square$ & $\square$ & $\square$ \\
11. Sleeping too much & $\square$ & $\square$ & $\square$ \\
\hline 12. Loss of sexual desire & $\square$ & $\square$ & $\square$ \\
13. Trouble achieving orgasm & $\square$ & $\square$ & $\square$ \\
14. Trouble with erections & $\square$ & $\square$ & $\square$ \\
\hline 15. Anxiety & $\square$ & $\square$ & $\square$ \\
16. Restlessness & $\square$ & $\square$ & $\square$ \\
17. Decreased energy & $\square$ & $\square$ & $\square$ \\
18. Increased appetite & $\square$ & $\square$ & $\square$ \\
19. Increased weight & $\square$ & $\square$ & $\square$ \\
\hline 20. Emotional indifference & $\square$ & $\square$ & $\square$ \\
\hline
\end{tabular}

PRISE$_{20}$ (Patient related Inventory of Side Effects) modified after Wisniewski et al.

Table 1.

This patient-administrated questionnaire was included in the STAR-D study (Bech et al. 2012) so that the baseline score was used to evaluate before augmentation of citalopram with either bupropion or buspirone to ensure that the side effects to eight weeks treatment with citalopram were tolerable. In rational polypharmacy it is important to accept only tolerable side effects before any augmentation with other drugs. 
In a post-hoc analysis of the STAR-D study, decreased energy was significantly reduced when citalopram was combined with bupropion (Bech et al. 2012). This symptom seems therefore to be an indication of lack of effect of citalopram rather than a side effect.

In a similar way, many of the items in PRISE $_{20}$ can be considered as physiological arousal symptoms of depression as covered by HAM-D $\mathrm{D}_{9}$ e.g. difficulty sleeping, restlessness, anxiety, gastrointestinal symptoms or sexual symptoms. In the therapy-resistant depressed patients it is important to understand the nature of these symptoms, i.e. part of the depressive illness or drug-induced symptoms.

\section{Polypharmacy as a rational treatment with antidepressants monitored by the HAM-D $17 /$ PRISE $_{20}$.}

Typically, antidepressants as monotherapy are now approved by the regulators (e.g. FDA) with reference to placebo-controlled clinical trials of patients with major depression. This makes comparative analyses between individual new generation antidepressants difficult. In some trials an active comparator (e.g. a TCA) has been included, which however, is compared with placebo using only the total HAM-D score as an outcome, not the profile score in accordance with the ABC version.

In clinical practice, if a patient with major depression has failed to respond fully to the initial antidepressant, the treating physician can either augment by adding another drug to the initial antidepressant as part of a polypharmacy approach, or switch to another antidepressant with a quite different mechanism of action.

The Sequenced Treatment Alternatives to Relieve Depression, the STAR ${ }^{*} \mathrm{D}$ study, is probably the most evidence-based trial to reflect the daily clinical practice. After failure to respond to monotherapy with the SSRI citalopram, patients went on to receive medication augmentation with bupropion-SR (sustained release) or buspirone in a controlled, doubleblind trial.

Bupropion is a non-sedative second generation antidepressant with a selective reuptake inhibition of noradrenaline and dopamine (Table 2). It has a profile on the A, B and C HAM$\mathrm{D}_{17}$ similar to that of the SSRIs or SNRIs. This profile is also similar to the first generation of MAO-Is. Bupropion, like the MAO-Is, has an effect on dopamine in contrast to the TCAs or SSRIs/SNRIs..

Within the antidepressants referred to as first generation, concomitant treatment with a TCA and an "irreversible" MAO-I (e.g. phenelzine or isocarboxazid) has rarely been used. If a patient with major depression fails to respond fully on the HAM-D 6 with a TCA but still had some benefit on HAM- $\mathrm{D}_{9}$, it is then acceptable to add phenelzine or isocarboxazid. However, it is not considered acceptable to add a TCA in a patient with only partial response to a MAO-I due to the risk of cardiovascular problems (e.g. severely increased blood pressure leading to stroke). On the other hand, if the MAO-I has been stopped for 2 weeks, then combination therapy with a TCA and the reinstated treatment with MAO-I is acceptable. The most frequently used TCA in this situation is amitriptyline.

If initial therapy has been with an SSRI/SNRI, then the combination with a MAO-I, either an irreversible (e.g. isocarboxazid) or a reversible (e.g. moclobemide), might prove fatal. As 
shown in the post hoc analysis of the STAR*D study data, there is no problem in a combination therapy with citalopram and bupropion SR.

The TCAs were found to be superior to the MAO-Is. Because of their antihistamine action, the TCAs have a very strong and early onset effect on the arousal symptoms compared to citalopram, paroxetine or the MAO-I moclobemid. The most effective antidepressant is still amitriptyline.

In Table 2 the second generation antidepressants mianserin and mirtazapine are also antihistaminergic, but with a less pronounced effect on HAM-D . However, mianserin differs from the TCAs by having no anticholinergic effect, which is important when treating elderly depressed patients due to the side effects of anticholinergics on cognitive functioning. However, as shown in Table 2, all antihistamines have weight gain as a serious side effect.

\begin{tabular}{|c|c|c|c|c|c|}
\hline \multirow[b]{2}{*}{$\begin{array}{l}- \\
+ \\
++ \\
+++\end{array}$} & \multirow{2}{*}{\multicolumn{2}{|c|}{$\begin{array}{l}\text { No clear effect } \\
\text { Clear effect, mild to moderate } \\
\text { Clear effect, moderate to marked } \\
\text { Clear effect, marked to excellent/severe }\end{array}$}} & \multicolumn{2}{|c|}{ HAM-D } & \multirow{2}{*}{$\begin{array}{l}\text { Side effects } \\
\text { Weight gain }\end{array}$} \\
\hline & & & $\begin{array}{c}\text { A } \\
\text { Pure } \\
\text { depression } \\
\text { symptoms }\end{array}$ & $\begin{array}{c}\text { B } \\
\text { Arousal } \\
\text { symptoms }\end{array}$ & \\
\hline \multicolumn{3}{|c|}{ MONOTHERAPY } & & & \\
\hline \multirow{2}{*}{\multicolumn{2}{|c|}{$\begin{array}{l}\text { First generation } \\
\text { antidepressants }\end{array}$}} & TCAs (amitriptyline) & +++ & ++ & ++ \\
\hline & & MAO-Is (isocarboxazid) & + & - & - \\
\hline \multirow{4}{*}{\multicolumn{2}{|c|}{$\begin{array}{l}\text { Second generation } \\
\text { antidepressants } \\
\text { Specific } \\
\text { reuptake } \\
\text { inhibitors }\end{array}$}} & $\begin{array}{l}\text { SSRIs } \\
\text { (citalopram/sertraline) }\end{array}$ & + & - & - \\
\hline & & $\begin{array}{l}\text { SNRIs } \\
\text { (venlafaxine/duloxetine }\end{array}$ & ++ & - & - \\
\hline & & DNRI (bupropion) & + & - & - \\
\hline & & NRI (reboxetine) & + & - & - \\
\hline \multirow{3}{*}{\multicolumn{2}{|c|}{$\begin{array}{l}\text { Second generation } \\
\text { antidepressants } \\
\text { Other }\end{array}$}} & Mianserin & + & ++ & ++ \\
\hline & & Mirtazapine & + & ++ & ++ \\
\hline & & Agomelatine & + & + & - \\
\hline \multicolumn{6}{|c|}{ CONCOMITANT THERAPY } \\
\hline \multirow{3}{*}{\multicolumn{2}{|c|}{ Specific }} & SSRI plus NRI & ++ & - & - \\
\hline & & SSRI plus DNRI & ++ & - & - \\
\hline & & $\begin{array}{l}\text { SNRI plus DNRI plus } \\
\text { agomelatine }\end{array}$ & ++ & + & - \\
\hline \multirow{2}{*}{\multicolumn{2}{|c|}{ Non-specific }} & $\begin{array}{l}\text { Mianserin/mirtazapine } \\
\text { plus SSRI/SNRI }\end{array}$ & +++ & ++ & ++ \\
\hline & & $\begin{array}{l}\text { Mianserin/mirtazapine } \\
\text { plus MAO-I }\end{array}$ & ++ & ++ & ++ \\
\hline \multirow{2}{*}{\multicolumn{2}{|c|}{$\begin{array}{l}\text { Monotherapy } \\
\text { Mood stabilizers }\end{array}$}} & Lithium & + & - & - \\
\hline & & Olanzapine & + & ++ & ++ \\
\hline \multirow{2}{*}{\multicolumn{2}{|c|}{$\begin{array}{l}\text { Concomitant } \\
\text { therapy }\end{array}$}} & Olanzapine plus SSRI & ++ & ++ & ++ \\
\hline & & Lithium plus SSRI & ++ & - & - \\
\hline
\end{tabular}

Rational polypharmacy of antidepressants in the acute therapy of major depression with reference to ABC HAM-D 17. Concerning the optimal dose of the included drugs, see Papakostas et al.

Table 2. 
Concomitant therapy with mianserin and the MAO-I isocarboxazid has been found safe, but with weight gain as a problem. Concomitant therapy with mianserin and the SSRI fluoxetine has been evaluated in placebo-controlled trials by Dam et al. In this pilot study 13 patients received fluoxetine plus mianserin, while 17 patients received fluoxetine plus placebo. On the HAM- $\mathrm{D}_{17}$ the distance from baseline to endpoint (six weeks) was greatest for fluoxetine plus mianserin. However, even in this study approximately $30 \%$ had increased weight gain on the combination of mianserine plus fluoxetine whereas no weight gain was seen in the fluoxetine plus placebo treated group. A re-analysis of the data set has shown that it is on the arousal symptoms (HAM- $\mathrm{D}_{9}$, domain B, Figure 2) that the effect of the combination therapy is greatest. In a comprehensive study Blier et al. have investigated the effect of monotherapy with fluoxetine compared to the combination of mirtazapine with fluoxetine or of mirtazapine with venlafaxine or of mirtazapine with bupropion. The results showed that the rate of remitters $\left(H A M-D_{17} \leq 7\right)$ increased from $25 \%$ with monotherapy to approximately $50 \%$ with any of the three mirtazapine combinations. However, in all these combination therapies weight gain was significantly increased compared to monotherapy with fluoxetine. Otherwise the combination therapy was safe.

A $\mathrm{HAM}_{-} \mathrm{D}_{6}$ (depression)

\begin{tabular}{|l|l|l|l|}
\hline & Flu + Mian & Flu + Pla & \multirow{2}{*}{ P } \\
\cline { 1 - 3 } Baseline & $12.6(2.2)$ & $12.0(1.4)$ & \\
\hline $\begin{array}{l}\text { \% } \\
\text { improvement } \\
\text { at endpoint }\end{array}$ & $56.3 \%$ & $57.5 \%$ & 0.35 \\
\hline
\end{tabular}

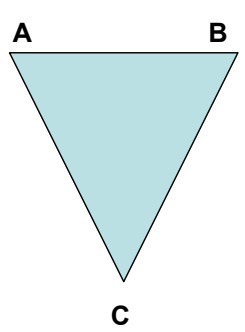

B HAM-D $_{9}$ (arousal)

\begin{tabular}{|l|l|l|l|}
\hline & Flu + Mian & Flu + Pla & \multirow{2}{*}{ P } \\
\cline { 1 - 3 } Baseline & $11.2(3.1)$ & $9.1(3.7)$ & \\
\hline $\begin{array}{l}\text { \% } \\
\text { improvement } \\
\text { at endpoint }\end{array}$ & $71.4 \%$ & $53.8 \%$ & 0.08 \\
\hline
\end{tabular}

C $\mathrm{HAM}_{2} \mathrm{D}_{2}$ (suicide)

\begin{tabular}{|l|l|l|l|}
\hline & Flu + Mian & Flu + Pla & \multirow{2}{*}{ P } \\
\cline { 1 - 3 } Baseline & $2.0(1.5)$ & $1.3(1.3)$ & \\
\hline $\begin{array}{l}\% \\
\text { improvement } \\
\text { at endpoint }\end{array}$ & $80.0 \%$ & $76.9 \%$ & 0.23 \\
\hline
\end{tabular}

Fig. 2. A re-analysis of the dataset in Dam et al. 1998 
In Table 2 the new generation antidepressant agomelatine is included. So far this drug has not been approved by the FDA as an antidepressant, but it is on the market in many European countries. Agomelatine acts by blocking the serotonin receptor 2, as mianserin or mirtazapine, but in contrast to these two drugs, without any antihistaminergic effects and therefore without weight gain as a side effect. However, agomelatine also has a selective effect on melatonin, thereby acting on sleep within the arousal symptoms in the HAM-D . We still have no firm data from controlled clinical trials on concomitant therapy with agomelatine and SSRIs/SNRIs, but clinical experience is indicated in Table 2. An anecdotal report of a safe combination of agomelatine and MAO-I is now available.

Table 2 also includes the mood-stabilizing drug lithium. The major indication for lithium therapy is its prophylactic effect in both bipolar and unipolar affective disorder. However, in the acute therapy of major depression, in a low dose (serum concentration of $0.4-0.5$ $\mathrm{mmol} / \mathrm{l})$, lithium is one of the most effective drugs, helping to obtain a response in therapyresistant depression. Its anti-suicidal effect is especially well-documented. The use of lithium in the acute therapy of major depression is referred to as augmentation, i.e. a nonconcomitant initial use, in which the decision to start lithium treatment follows an initial treatment trial with one antidepressant resulting in only partial response.

Whereas concomitant therapy of lithium and an antidepressant seems most obvious in bipolar depression or depressed patients with hidden bipolarity, a concomitant therapy of olanzapine and an antidepressant (fluoxetine) has been shown to be effective not only in bipolar depression, but also in major depression . In the latter study, the HAM-D ${ }_{24}$ version was actually used, in this version specific items for hopelessness, helplessness and worthlessness have been included to strengthen domain A (Figure 1).

The term 'atypical antidepressants' refers to the use of MAO-Is (especially phenelzine) in the treatment of atypical major depression - i.e. patients with pure depression symptoms (A in Figure 1) but with inverse physiological symptoms (hypersomnia and increased appetite). As a non-antihistaminergic drug, agomelantine might be used in combination with MAO-Is in the treatment of atypical depression.

\section{Polypharmacy: Pharmacokinetic considerations}

According to pharmacokinetic studies the TCAs are mainly metabolized by CYP 450 enzyme system with the 2D6 substrate. Both agomelatine and mirtazapine are metabolized by the 1A2 substrate and therefore have no problems with CYP2D6 genetic polymorphisms. Among SSRIs we have listed citalopram and sertraline in brackets in Table 2 because these two antidepressants have the most acceptable pharmacokinetic profile. Among the SNRIs we have included both duloxetine and venlafaxine although desvenlafaxine might turn out to have the fewest drug-drug interactions in this class of antidepressants. Reboxetine and bupropion are metabolized through CTP3A4 but this seems only to be a problem when combined with the SSRI fluvoxamine. It is, however, recommended to consult specific reviews on pharmacokinetics when starting rational polypharmacy. In this review we have considered practical experience to be a valid guide. Thus, no problems with mirtazapine were found in the Blier et al. study. Mianserine was found to be safe both when combined with MAO-Is and with SSRIs (fluoxetine or citalopram). A combination of olanzapine and fluoxetine is also acceptable. 


\section{Conclusion}

The most selective second generation antidepressants have not proved in monotherapy to be more effective on the core symptoms of depression than the first generation TCAs or MAOIs. It is by their safety profiles, either in overdose or in terms of long term side effects, that the second generation antidepressants have outperformed the first generation.

If we accept that amitriptyline is the most effective antidepressant ever marketed, we need to use rational polypharmacy with the second generation antidepressants in the acute therapy of major depression in order to obtain effectiveness similar to that of amitriptyline, but without problematic side effects such as anticholinergic actions. A combination of mianserine/mirtazapine and SSRI/SNRI (Table 2) is the most rational polypharmacy when compared to amitriptyline. On the other hand, weight gain as a serious side effect is also prevalent here.

If a sedative effect on the HAM-D subscale of arousal symptoms (HAM-D 9 ) is needed, agomelatine might be used in combination with the specific reuptake inhibitors (Table 2). Reboxetine, for example, is a very weak antidepressant but when combined with an SSRI there is anecdotal evidence that patients respond much more favourably than on the SSRI in monotherapy.

The A,B,C HAM-D combined with PRISE $_{20}$ should be used whenever rational polypharmacy is employed.

\section{References}

[1] Trivedi MH, Fava M, Wisniewski SR, Thase ME, Quitkin F, Warden D, et al. Medication augmentation after the failure of SSRIs for depression. N Engl J Med. 2006 Mar 23;354(12):1243-52.

[2] Papakostas GI, Bech P, Fava M. Pharmacological treatment of major depressive disorder: A review. In: Herman H, Maj M, Sartorius N, editors. WPA Series Evidence and Experience in Psychiatry. Chichester: Wiley-Blackwell; 2009. p. 47-74.

[3] Barbui C, Hotopf M. Amitriptyline vs. the rest: Still the leading antidepressant after 40 years of randomised controlled trials. Br J Psychiatry. 2001;178:129,129-144.

[4] Larsen JK, Bendsen BB, Bech P. Vitamin B6 treatment of oedema induced by mirtazapine and isocarboxazid. Acta Psychiatr Scand. 2011 Jul;124(1):76,7; discussion 77.

[5] DUAG. Citalopram: Clinical effect profile in comparison with clomipramine. A controlled multicenter study. danish university antidepressant group. Psychopharmacology (Berl). 1986;90(1):131-8.

[6] DUAG. Paroxetine: A selective serotonin reuptake inhibitor showing better tolerance, but weaker antidepressant effect than clomipramine in a controlled multicenter study. Danish University Antidepressant Group. J Affect Disord. 1990 Apr;18(4):28999.

[7] Hordern A, Burt CG, Holt NF, Cade JF. Depressive states: A pharmacotherapeutic study. Springfield: Charles C Thomas; 1965. 
[8] Moncrieff J, Cohen D. Do antidepressants cure or create abnormal brain states? PLoS Med. 2006 Jul;3(7):e240.

[9] Hamilton M. Development of a rating scale for primary depressive illness. Br J Soc Clin Psychol. 1967 Dec;6(4):278-96.

[10] Bech P. The ABC profile of the HAM-D17. Revista Brasileira de Psiquiatria. 2011;33(2):109-10.

[11] Bech P. The threefold Hamilton Depression Scale. Acta Psychiatrica Scandinavica. 2012 In press.

[12] Bech P. Fifty years with the Hamilton scales for anxiety and depression. A tribute to Max Hamilton. Psychother Psychosom. 2009;78(4):202-11.

[13] Bech P, Gram LF, Dein E, Jacobsen O, Vitger J, Bolwig TG. Quantitative rating of depressive states. Acta Psychiatr Scand. 1975 Mar;51(3):161-70.

[14] Bech P, Allerup P, Gram LF, Reisby N, Rosenberg R, Jacobsen O, et al. The Hamilton Depression Scale. evaluation of objectivity using logistic models. Acta Psychiatr Scand. 1981 Mar;63(3):290-9.

[15] Bech P, Allerup P, Reisby N, Gram LF. Assessment of symptom change from improvement curves on the Hamilton Depression Scale in trials with antidepressants. Psychopharmacology (Berl). 1984;84(2):276-81.

[16] Paykel ES. Use of the Hamilton Depression Scale in general practice. In: Bech P, Coppen A, editors. The Hamilton Scales. Berlin: Springer; 1990. p. 40-9.

[17] Bech P. Meta-analysis of placebo-controlled trials with mirtazapine using the core items of the Hamilton Depression Scale as evidence of a pure antidepressive effect in the short-term treatment of major depression. Int J Neuropsychopharmacol. 2001 Dec;4(4):337-45.

[18] Santen G, Gomeni R, Danhof M, Della Pasqua O. Sensitivity of the individual items of the Hamilton Depression Rating Scale to response and its consequences for the assessment of efficacy. J Psychiatr Res. 2008 Oct;42(12):1000-9.

[19] Andreasson K, Liest V, Lunde M, Martiny K, Unden M, Dissing S, et al. Identifying patients with therapy-resistant depression by using factor analysis. Pharmacopsychiatry. 2010 Sep 6;43:252-6.

[20] Healy D. Did regulators fail over selective serotonin reuptake inhibitors? BMJ. 2006 Jul 8;333(7558):92-5.

[21] Rush AJ, Fava M, Wisniewski SR, Lavori PW, Trivedi MH, Sackeim HA, et al. Sequenced treatment alternatives to relieve depression $\left(\mathrm{STAR}^{*} \mathrm{D}\right)$ : Rationale and design. Control Clin Trials. 2004 Feb;25(1):119-42.

[22] Wisniewski SR, Rush AJ, Balasubramani GK, Trivedi MH, Nierenberg AA, for the $S T A R * D$ Investigators. Self-rated global measure of the frequency, intensity, and burden of side effects. J Psychiatr Pract. 2006 Mar;12(2):71-9.

[23] Bech P. Rating scales for psychopathology, health status and quality of life. A compendium on documentation in accordance with the DSM-III-R and WHO systems. Berlin: Springer; 1993.

[24] Bech P, Gefke M, Lunde M, Lauritzen L, Martiny K. The pharmacopsychometric triangle to illustrate the effectiveness of T-PEMF concomitant with antidepressants in treatment resistant patients: A double-blind, randomised, sham-controlled trial 
revisited with focus on the patient-reported outcomes. Depression Research and Treatment. 2011:Article ID 806298, 6 pages doi:10.1155/2011/806298.

[25] Bech P, Fava M, Trivedi MH, Wisniewski SR, Rush AJ. Outcomes on the pharmacopsychometric triangle in bupropion-SR vs. buspirone augmentation of citalopram in the STAR ${ }^{\star}$ D trial. Acta Psychiatr Scand. 2011 Nov 12.

[26] Bech P, Boyer P, Germain JM, Padmanabhan K, Haudiquet V, Pitrosky B, et al. HAMD17 and HAM-D6 sensitivity to change in relation to desvenlafaxine dose and baseline depression severity in major depressive disorder. Pharmacopsychiatry. 2010;43(7):271-6.

[27] White K, Simpson G. Combined MAOI-tricyclic antidepressant treatment: A reevaluation. J Clin Psychopharmacol. 1981 Sep;1(5):264-82.

[28] Stern SL, Mendels J. Drug combinations in the treatment of refractory depression: A review. J Clin Psychiatry. 1981 Oct;42(10):368-73.

[29] Neuvonen P, Pohjola-Sintonen S, Tacke U. Five fatal cases of serotonin syndrome after moclobemide-citalopram or moclobemide-clomipramine overdoses. Lancet. 1993;342:1419.

[30] Medical Research Council. Clinical trial of the treatment of depressive illness. BMJ. 1965;1:881-6.

[31] DUAG. Moclobemide: A reversible MAO-A-inhibitor showing weaker antidepressant effect than clomipramine in a controlled multicenter study. danish university antidepressant group. J.Affect.Disord. 1993;28:105-116.

[32] Riise IS, Holm P. Concomitant isocarboxazid/mianserin treatment of major depressive disorder. J Affect Disord. 1984 Apr;6(2):175-9.

[33] Dam J, Ryde L, Svejso J, Lauge N, Lauritsen B, Bech P. Morning fluoxetine plus evening mianserin versus morning fluoxetine plus evening placebo in the acute treatment of major depression. Pharmacopsychiatry. 1998 Mar;31(2):48-54.

[34] Blier P, Ward HE, Tremblay P, Laberge L, Hebert C, Bergeron R. Combination of antidepressant medications from treatment initiation for major depressive disorder: A double-blind randomized study. Am J Psychiatry. 2010 Mar;167(3):281-8.

[35] Olié J-. Combining agagomelatine in the evening + iproniazide in the morning. 2011.

[36] Bech P. The full story of lithium. A tribute to Mogens Schou (1918-2005). Psychother Psychosom. 2006;75(5):265-9.

[37] Bech P, Christensen EM, Vinberg M, Bech-Andersen G, Kessing LV. From items to syndromes in the Hypomania Checklist (HCL-32): Psychometric validation and clinical validity analysis. J Affect Disord. 2011 Feb 22;132:48-54.

[38] Tohen M, Vieta E, Calabrese J, Ketter TA, Sachs G, Bowden C, et al. Efficacy of olanzapine and olanzapine-fluoxetine combination in the treatment of bipolar I depression. Arch Gen Psychiatry. 2003 Nov;60(11):1079-88.

[39] Rothschild AJ, Williamson DJ, Tohen MF, Schatzberg A, Andersen SW, Van Campen LE, et al. A double-blind, randomized study of olanzapine and olanzapine/fluoxetine combination for major depression with psychotic features. J Clin Psychopharmacol. 2004 Aug;24(4):365-73. 
[40] Årsland D, Larsen JP, Lim NG, Wermuth L, Bech P. a2-adrenoreceptor antagonism and serotonin reuptake inhibition in patients with parkinson disease and depression. Nord J Psychiatry. 2000;54:411-5.

[41] Eyding P, Lelgemann M, Grouven U, Härter M, Kromp M, Kaiser T, et al. Reboxetine for acute treatment of major depression: Systematic review and meta-analysis of published and unpublished placebo and selective serotonin reuptake inhibitor controlled trials. British Medical Journal. 2010;341:4737. 


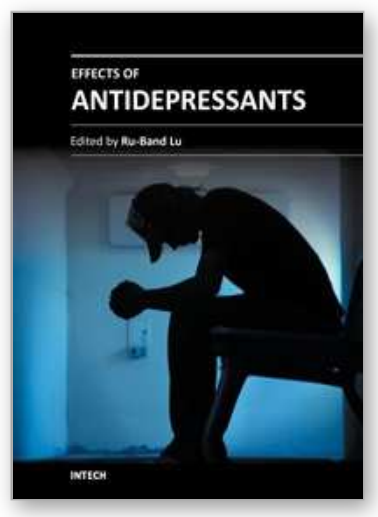

\author{
Effects of Antidepressants \\ Edited by Dr. Ru-Band Lu
}

ISBN 978-953-51-0663-0

Hard cover, 194 pages

Publisher InTech

Published online 29, June, 2012

Published in print edition June, 2012

Over the last fifty years, many studies of psychiatric medication have been carried out on the basis of psychopharmacology. At the beginning, researchers and clinicians found the unexpected effectiveness of some medications with therapeutic effects in anti-mood without knowing the reason. Next, researchers and clinicians started to explore the mechanism of neurotransmitters and started to gain an understanding of how mental illness can be. Antidepressants are one of the most investigated medications. Having greater knowledge of psychopharmacology could help us to gain more understanding of treatments. In total ten chapters on various aspects of antidepressants were integrated into this book to help beginners interested in this field to understand depression.

\title{
How to reference
}

In order to correctly reference this scholarly work, feel free to copy and paste the following:

Per Bech and Claudio Csillag (2012). Rational Polypharmacy in the Acute Therapy of Major Depression, Effects of Antidepressants, Dr. Ru-Band Lu (Ed.), ISBN: 978-953-51-0663-0, InTech, Available from: http://www.intechopen.com/books/effects-of-antidepressants/rational-polypharmacy-in-the-acute-therapy-ofmajor-depression

\section{INTECH}

open science | open minds

\section{InTech Europe}

University Campus STeP Ri Slavka Krautzeka 83/A 51000 Rijeka, Croatia Phone: +385 (51) 770447 Fax: +385 (51) 686166 www.intechopen.com

\section{InTech China}

Unit 405, Office Block, Hotel Equatorial Shanghai No.65, Yan An Road (West), Shanghai, 200040, China 中国上海市延安西路65号上海国际贵都大饭店办公楼405单元 Phone: +86-21-62489820

Fax: +86-21-62489821 
(C) 2012 The Author(s). Licensee IntechOpen. This is an open access article distributed under the terms of the Creative Commons Attribution 3.0 License, which permits unrestricted use, distribution, and reproduction in any medium, provided the original work is properly cited. 